\title{
ANALYSIS OF MATHEMATICAL CONNECTIONS ABILITY ON JUNIOR HIGH SCHOOL STUDENTS
}

\author{
Maria Agustina Kleden ${ }^{1}$, Yoseph Sugi ${ }^{2}$, Damianus D Samo ${ }^{*}$ \\ 'Universitas Nusa Cendana, Kupang, Indonesia \\ * damianus.damo@staf.undana.ac.id
}

\begin{tabular}{l}
\hline Article Info \\
\hline Article history \\
Received March 5, 2021 \\
Revised April 26, 2021 \\
Accepted May 1, 2021 \\
\hline
\end{tabular}

Keywords: mathematical connection ability; Mathematics analysis; Students ability

\begin{abstract}
Mathematical connection is the ability to make connections to understanding mathematical concepts that are associated with contexts outside of mathematics. Various studies revealed that the students' mathematical connection is still low; therefore, this study aims to describe the difficulties of junior high school students in mathematical connection ability. This research is a descriptive qualitative study. The study sample was 52 students from a junior high school in East Flores Regency. The methods used in this study were tests, observations, and interviews. The study results showed that the mathematical connection ability based on the three indicators of connection ability tends to be below. Students did not understand concepts that had been studying; easy to forget concepts, principles and procedures; not used to use concepts, principles and procedures; assume mathematics has nothing to do with other sciences; not accustomed to applying mathematical concepts in everyday life; lack of understanding about the story.
\end{abstract}

\section{INTRODUCTION}

Education produces human resources that utilize various natural resources to improve life welfare but still maintains and preserves the environment as a challenge in the world of education. Forming quality human resources means forming humans with mathematical abilities because mathematical abilities have a significant relationship with motor skills even from childhood (Reikerås, Moser, \& Tønnessen, 2017). Mathematical abilities correlated with various life outcomes vary across individuals (Looi \& Kadosh, 2016). The prominent role of mathematical ability is also expressed by (Williams 2015)that mathematics predicts future creative contributions and leadership in an important role in work. Having mathematical competencies requires meaningful mathematics learning. The meaningful mathematics learning approach involves cognitive aspects, namely consideration of students' cognitive structures related to previously learned concepts that can be used as prerequisites for new concepts; socio-constructivist, namely contexts saw as everyday social situations that make sense to the learner, and that invite him or her to engage in an active process of knowledge construction, and socio-cultural, namely the consideration that learning is a participatory process (Polman, Hornstra, \& Volman, 2020). Learning uses the surrounding environment 
contextually, which will build a good understanding of the material being studied and the behavior of maintaining and maintaining the surrounding environment. Meaningful learning like this is needed to practice reasoning, communicating, connecting, and solving various problems related to the problems they face in their environment (NCTM, 2000)

Mathematical connection ability is one of the five abilities students have to possess in learning mathematics. The ability to make connections is a way to create understanding through linking mathematical concepts with old concepts learned, other fields of science, and the environment. Mathematical connection ability is needed because mathematics is not a separate collection, although it was often partition. In contrast, mathematics is an integrated field of study with ideas interconnected as a coherent whole (NCTM, 2000). Mathematical connections have a significant role in learning mathematics and solving mathematical problems and in other sciences and everyday life (Baiduri, Putri, \& Alfani, 2020). A connection among different mathematical concepts helps students develop their understanding of how to link these concepts to previous knowledge (Zengin, 2019). If students can connect concepts in mathematics, they will have a deeper understanding and can last extended knowledThis ability is essential because by knowing mathematical relationships, students will better understand mathematics also give them greater mathematical power (Siregar \& Siagian, 2019).

Teachers and the government have made various efforts to improve students' mathematical competency, but these efforts have not provided optimal results. The national mathematics test results at both junior and senior high school levels are still low compared to other subjects. It is because what the teacher teaches is not a mathematical concept but a mathematical procedure. Mathematical concepts consist of mathematical objects (mental) and the relationships between these objects (Simon, 2017). Students' difficulties may not involve one particular math skill, but they may construct several skills (Tambychik, Meerah, \& Aziz, 2010). Understanding mathematics is not reducible to mathematical definitions and theorems (Vergnaud, 1997). This situation makes it difficult for students to solve mathematical problems.

Students were facilitating to connect a concept with other concepts in order to have a meaningful understanding. Meaningful understanding is obtained from students by linking things that are contextual related to everyday life. The concept of mathematics will be easier to learn when it is associated with everyday problems experienced by students. Thus, this mathematical concept will stay in students' long-term memory so that it helps solve problems faced that are increasingly complex.

Various studies have revealed students' mathematical connection abilities. (Jalaludin, Yunita, Indahsari, \& Purwasih, 2018) The ability of students to connect in solving flat-sided shape problems is in a suitable category, which shows that students have understood the concept well. Baiduri. et al. (2020)explored students' connection abilities based on gender 
differences. Male and female students have similar mathematical connection processes when making mathematical relationships with other sciences and with everyday life and when connecting in mathematics at the rechecking stage. At the same time, the difference in the connection process in mathematics between male and female students is carried out at the stage of understanding the problem, solving strategies, and implementing problem-solving. Islami, Sunardi, \& Slamin (2018) revealed that students with high logical intelligence have internal and external connections in solving geometric problems based on their pattern of steps.

Some of these studies and many other similar studies have the same idea, namely exploring mathematical connection abilities based on Polya's steps with a review of the characteristics of different subjects and mathematical materials. These studies have not explored mathematical connection abilities and have revealed failed connections from students in the math process. This study tries to map the mathematical context skills and portraits of students' mistakes or weaknesses in constructing their ideas according to the indicators of mathematical connection ability.

\section{METHODS}

This research is a descriptive qualitative study carried out in one of the SMPN in East Flores Regency. The sample of this study was 52 students of class VII. It aims to describe the difficulties of the mathematical connection ability of middle school students. Mathematical connection is the ability to recognize, use, and make connections between and among mathematical ideas and in contexts outside mathematics to build mathematical understanding. Mathematical connection ability is measured from three indicators, namely 1) recognize and use connections among mathematical ideas, 2) recognize and apply mathematics in contexts outside of mathematics, 3) demonstrate how mathematical ideas interconnect and build on one another to produce a coherent whole (NCTM, 2003). The difficulty measured on each indicator of the mathematical connection includes understanding and using concepts, principles, procedures, and other aspects of difficulty found in the problem-solving process. The three indicators of mathematical connection ability are specified in 3 questions that three validators have validated. The methods used in this study are tests, documentation, and interviews. Data is reduced to display test results scores from each indicator of mathematical communication skills. Students were categorized into five categories (good, good, enough, trimmer, and more minor). Then two people were selected with the lowest test scores from each aspect to be interviewed. Data from tests and interviews were analyzed descriptively. The data validation used triangulation methods. 


\section{RESULTS AND DISCUSSION}

\section{RESULTS}

The test results showed that students' mathematical connection competency belongs to different categories, namely suitable, sufficient, trimmer, and fewer categories. Students' mathematical connection abilities based on indicators are sorted from highest to lowest as follows.

1. Indicator 2: categorized as sufficient with an average of 65.25

2. Indicator 1: categorized as very low with an average of 40.75 .

3. Indicator 3: categorized as very low with an average of 34.25.

Completion of question number 1 obtained several errors made by students, as shown in Figure 1.

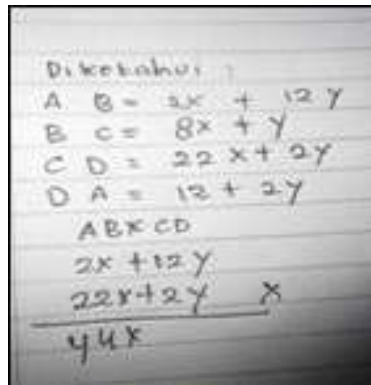

a

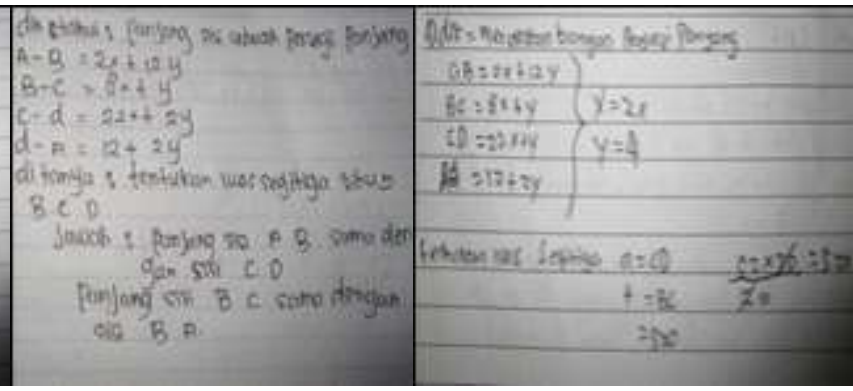

$\mathrm{b}$

C

Figure 1. The snippet of Completion number 1

The first problem presents a rectangle whose length and width are represented algebraically. The rectangles are $22 x+2 y$ and $2 x+2 y$ and the widths are $12+2 y$ and $8 x+y$. Students had been asking to find half the area of the rectangle.

Figure 1 shows that students can obtain information given as questions but misuse the concept in solving the problem. Students understand the information given in questions and what is asked. Student b looks capable of writing correct principles but cannot understand the procedures; the absence of other solutions indicates this. Students can know the information given in questions and can solve the problem but use the wrong procedure.

Based on mistakes made in the number 1 problem, the students seemed confused and made various mistakes in answering the questions. The answers illustrate difficulties in using concepts, principles, and procedures. Students seem challenging to use algebraic concepts but look good in using the concept of the wide-awake right triangle. In addition, students seem to find difficulties in the relationship between concepts, namely using the properties of a rectangle to determine the values of $x$ and $y$; besides, students also find difficulty finding procedures in determining the value of $x$ and $y$ in a two-variable linear equation system. Difficulties using procedures are indicated by steps that are wrong in working on the problem. Students do not understand the purpose of the question asked to find $x$ and $y$ values first then link to find the area of a right triangle. 
Students can show the connection between algebra and geometry material, as shown in the following interview excerpt.

\section{Student 1}

Question: What do you think the material contained in the question?

Answer: rectangle, and equation $x, y$

Question: What is the connection between the materials you mentioned?

Answer: $x$ and $y$ represent the length of the side of the rectangle.

In student 2, he revealed that the question gave an order to find a right triangle $B C D$ area. He solved the problem with First, write down the sides of $A B, B C, C D, A D$. Second, specify the sides of the same length of rectangle $A B=C D$ and $B C=D A$. However, he could not finish the problem because he did not know the next step. Nonetheless, he knows the connection between the algebraic form and the geometric shapes of rectangles and triangles where $x$ and $y$ represent the lengths of the sides of a rectangle and triangle.

\section{Student 2}

Question: In your opinion, what material is contained in the problem?

Answer: Rectangle, Triangle and variables $x$ and $y$

Question: What is the connection between the material you mentioned?

Answer: $x$ and $y$ represent the lengths of the sides of a rectangle and triangle

Student 2 was able to interpret the intent of the problem and use the correct principle on the rectangular material. However, it seems confusing to determine how to solve the problem, obtained that students two experience complicated procedures. The absence of further settlement evidence it

Completion of question number 2 obtained several errors made by the research subject shown in Figure 2

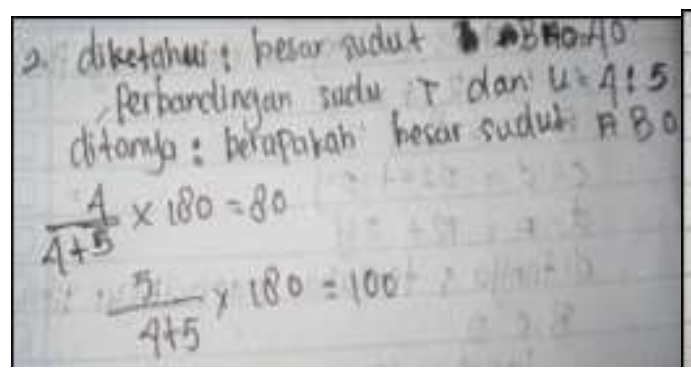

a

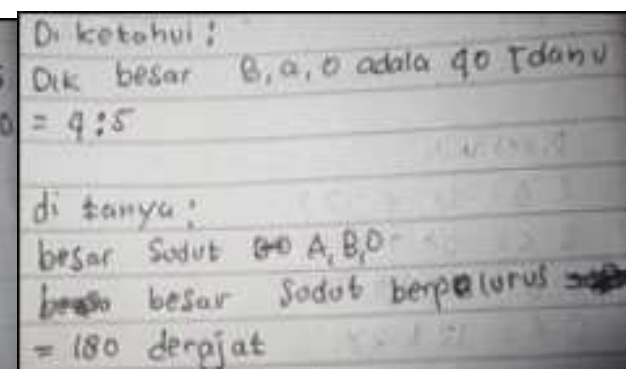

b

Figure 2. The snippet of Completion Number 2

The second problem presents a triangle $A B C$ with angle $A 400$, and point $O$ is the intersection of line $B O$ and line $A C$ so that it forms angles $A O B$ and $B O C$ with a ratio of $4: 5$. Students are asked to find the angles in the triangle.

Figure 2 shows that students can obtain information given through questions and know the purpose of the problem. Students can use big concepts of straightforward angles but cannot find solutions because of confusing procedures and significant concepts of angles in a triangle. Students can only obtain information given in the question, know the purpose of the question, and know the big concept of aligned angles. Based on the footage above, students 
have difficulty in determining the intended angle. Students have understood the concept of comparison. Students have used the principle of the number of mutually aligned angles, namely $180^{\circ}$, or the size of a semicircle angle is $180^{\circ}$. However, students have difficulty using the principle of the number of angles in a triangle that is $180^{\circ}$. The absence of further settlement indicates it.

Based on the results of interviews with students who have low scores for question number 2 , student 1 reveals the information on the question very clearly where the angle ratio is 4: 5 and is asked to find the $A B O$ angle. He then wrote down the thing known in the problem, for example, the BAO angle and the angle $t=4$ and $u=5$; after that, a comparison to determine the magnitude of the angle $t$ and $u$. The ratio of 9 is obtained from $4+5$ and scores 80 and 100. He cannot finish the problem until it is finished because he does not know the next step. He forgot how to find the angle (pointing to point $B$ in the image).

Student 1

Question: Is there material that you remember and something you forgot?

Answer: Because the new teacher teaches material about comparison

Question: Do you study material by connecting the material now and what you have learned?

Answer: Yes, ma'am

Based on the interview excerpt, student 1 forgets the principle of determining the size of one corner in a triangle if the other angles are known. It found that student 1. quickly remembered the concepts or material been taught by the teacher. Students forget the concept, so that it is difficult to use the procedure.

In student 2, he revealed that the question asked to find the angle of $A B O$ with information that is known the angle of $\mathrm{BAO}=40^{\circ}$, angle $\dagger$ and $u=4$ and 5 . However, he was unable to solve the problem.

Student 2

Question: Why can't you solve the problem?

Answer: I forgot, I only know that the straight line has a large angle of $180^{\circ}$ (while pointing to the AC side in the image)

Based on the interview excerpt, student 2 had difficulty remembering the concept, so they could not solve the problem.

Completion of question number 3 found some errors made by the research subjects shown in Figure 3 


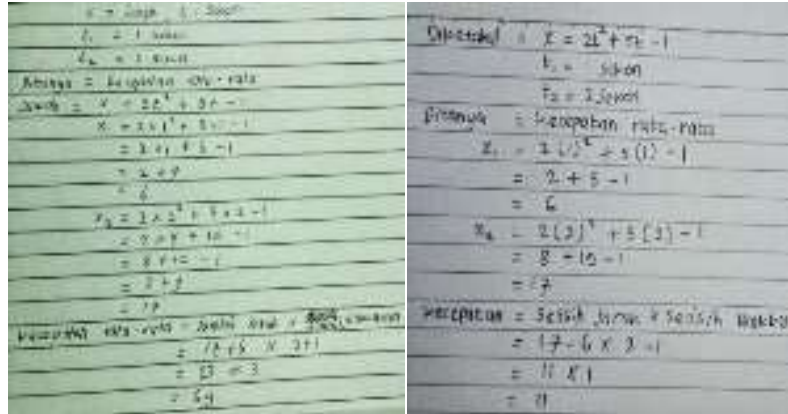

a

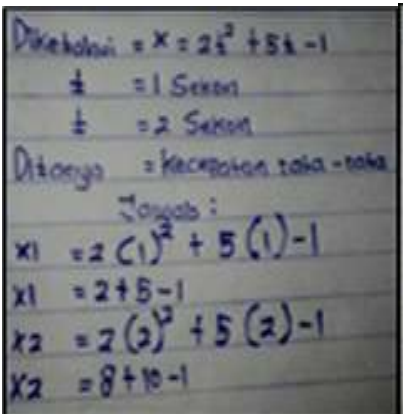

C

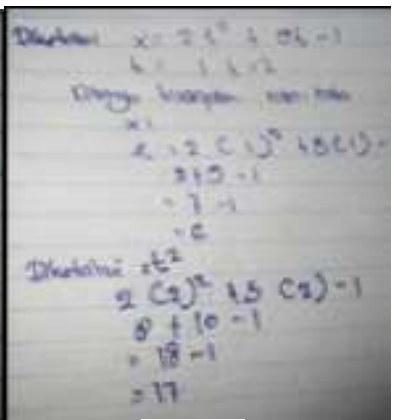

d

Figure 3. The snippet of Completion Number 3

The third problem presents an algebraic equation of the straight motion of a bicycle, $x=2+2+$ $5 t-1$, and students are asked to determine the average velocity at $t=1 \mathrm{~s}$ and $t=2 \mathrm{~s}$.

Based on Figure 3, students can receive information given through questions, use mathematical concepts and procedures well, but make misconceptions in searching for average speed. Students b can receive information given through questions, use mathematical concepts and procedures well but make misconceptions in searching for average speed. Students can obtain information from the problem but have difficulty calculating, which is indicated by the absence of other solutions. Student d experiences difficulties in using the procedure; no further completion indicates this after obtaining the value of $x$.

Based on the mistakes made in solving question number 3, students look good in linking mathematical material with other subject matter, in this case, physics subject matter about average speed, but have difficulty using formulas to solve the problem. It saw that students incorrectly used the average velocity formula obtained from the final position minus initial position divided by the end time minus initial time.

The excerpts of interviews were two students who had the lowest score from aspect 2 for solving problem number 3

Student 1

Question: Tell me how you solved the problem?

Answer: I wrote down what was known before and then searched for the value of $X$ by replacing $t=1$ and $t=2$

Question: How many results did you get?

Answer: I did not work until I have been doing it.

Based on the excerpts of interviewing students, 1 had difficulty in calculating. The absence of further settlement indicates it.

Student 2

Question: Does it have anything to do with other fields of study? If there are, try to mention them!

Answer: Yes, there is a ma'am with physics subjects

Question: How do you solve the problem? Explain It! 
Answer: Write down the position of the bicycle $(x)$, and time $t=1$ and $t=2$. Then I look for the value of the first $x$ by replacing $t=1$, so does the second $x t=2$

Question: Why don't you continue to solve the problem?

Answer: I do not know the next step, ma'am. I am confused between adding or subtracting the results I get.

The interview excerpt shows that student 2 has understood the procedure in determining the value of $x$ but has difficulty using the concept to find the average speed. Students are confused in determining the operation used in solving the problem.

\section{DISCUSSION}

The results showed that the students' mathematical connection ability was still in the low category. The average for each connection capability indicator can be seen, which tends to be below the average category. It shows that the subject has not connected mathematical ideas between mathematical content and other fields outside mathematics content. This finding is in line with the research theme of Yumiati \& Haji(2018), which revealed the ability of students for each school level and overall is in the medium category. Students' mathematical connection activities in the problem-solving process vary with the solving method according to their learning experience (Rangkuti, Susanto, \& Yuliati, 2018). Students use the whole algebraic approach to represent geometric problem-solving ideas. In this context, geometry visualization helps algebraic understanding should be developed to promote the use of visualization, including the development of the ability to make mathematical connections and improve students' mathematical understanding skills (García-garcía \& Dolores-Flores, 2019). The low ability of students' mathematical connections shows a general symptom of students' weak mastery of mathematical concepts due to a lack of effort to develop mathematical thinking skills with a tendency to present calculation procedures as a characteristic of mathematics. Learning also does not link new mathematical concepts and previously learned mathematical structures (Acharya, 2017).

The problems presented produce different responses that show the strengths and weaknesses of the students' mathematical connections. These problems generate a wide variety of responses and seem to require students to operate metacognitively, to recognize the mathematical tools they are learning and the paths to solutions (Schroeder, 1993). However, students' responses tend to be wrong, identifying as students who did not understand concepts studied; easy to forget concepts. A weak understanding of concepts makes students have difficulty connecting mathematical knowledge. The condition appears in the first problem solving in which students lose their conception that different algebraic forms are the same because they represent the same rectangular length. Students with weak conceptual knowledge about a topic are likely not to continue learning more because previous knowledge does not support them in processing and using new information related to the topic (Booth, 2014). Another difficulty that was found was the lack of mathematical 
procedural skills. The skill has been influenced by the habit of doing technical mathematics with various manipulations to get a solution. Weaknesses in mathematical procedures impact the flow of problem-solving even though conceptually problem-solving roadmaps are controlled.

In the stage of Polya (1954), understanding the problem is followed by planning and implementation. The first two stages can run well, but the calculation process is often another problem. This condition appears in the second and third problem solving, which is correct in concept but fails in technical mathematical calculations. Finally, students' perceptions about mathematics are not related to other fields of science and everyday life. Teacher teaching is the formation of the essential perceptions of students (Setapa, Mustapha, Kanafiah, \& Zaman, 2016). Learning activities that make mathematics a core subject are not assistive in solving everyday context problems and in various fields have trapped students in a wrong understanding of mathematics. Students who are accustomed to conceptual problems lose the opportunity to look at mathematics in context. The significant results of the study showed that the students' difficulties are on the inability to translate the problem into mathematical form and inability to use correct mathematics (Siniguian, 2017) (Bossé, Adu-Gyamfi, \& Cheetham, 2011; Cruz \& Lapinid, 2014; Jupri \& Drijvers, 2016). Based on the results of tests and interviews conducted by researchers to students regarding mathematical connections, students still consider material in mathematics as a separate set of material so that they have difficulty in solving proposed problems, both in terms of relating material to one another in mathematics and with other fields of science and problems in everyday life.

\section{CONCLUSION}

The mathematical connection ability of grade VII students at junior high schools in the East Flores region varies as indicated by the achievement of the mathematical connection ability indicators. In indicator 1 , students are in the low category with an average achievement, 40.75; on indicator two students are in the medium category with an average achievement of 65.25; whereas in indicator 3, students are in the deficient category with an average achievement of 34.25. Mathematics learning difficulties experienced by students in terms of mathematical connection skills include the following: 1) lack of understanding concepts that have been learning; 2) easy to forget concepts that have been learning or which rarely repeated; 3) rarely associate concepts to have been studying with concepts have been learned; 4) difficulties using principles and procedures in solving problems; 5) lack of understanding verbal questions; 6) not getting used to understanding concepts, principles, and procedures, 7 ) less aware of benefits of mathematics concerning other fields of science; 8) less aware of benefits of mathematics concerning everyday life.

\section{REFERENCES}


Acharya, B. R. (2017). Factors Affecting Difficulties in Learning Mathematics by Mathematics Learners. International Journal of Elementary Education, 6(2), 8-15. https://doi.org/doi: 10.11648/j.jijeedu.20170602.11

Baiduri, Putri, O. R. U., \& Alfani, I. (2020). Mathematical Connection Process of Students with High Mathematics Ability in Solving PISA Problems. European Journal of Educational Research, 9(4), 1527-1537. https://doi.org/https://doi.org/10.12973/eu-jer.9.4.1527

Booth, J. L. (2014). Why Can't Students Get the Concept of Math ?, (June).

Bossé, M. ., Adu-Gyamfi, K., \& Cheetham, M. . (2011). Assessing the Difficulty of Mathematical Translations: Synthesizing the Literature and Novel Findings. International Electronic Journal of Mathematics Education, 6(3), 113-133.

Cruz, J. K. B. D., \& Lapinid, M. R. C. (2014). Students' Difficulties in Translating Worded Problems into Mathematical Symbols. In P Research Congress 2014 De La Salle University, Manila, Philippines.

García-garcía, J., \& Dolores-Flores, C. (2019). Pre-university students ' mathematical connections when sketching the graph of derivative and antiderivative functions. Mathematics Education Research Journal. https://doi.org/10.1007/s13394-019-00286-x

Islami, M. D., Sunardi, \& Slamin. (2018). The Mathematical Connections Process of Junior High School Students with High and Low Logical-Mathematical Intelligence in Solving Geometry Problems, 6495(4), 10-18.

Jalaludin, M. A., Yunita, W., Indahsari, I. N., \& Purwasih, R. (2018). Analysis of Mathematical Connection Confidence in Flat-Side Space Material and Students 'Self, 2(3), 114-119.

Jupri, A., \& Drijvers, P. (2016). Student Difficulties in Mathematizing Word Problems in Algebra. Eurasia Journal of Mathematics, Science \& Technology Education, 12 (9), 2481-2502. https://doi.org/10.12973/eurasia.2016.1299a

Looi, C. Y., \& Kadosh, R. C. (2016). Brain stimulation, mathematical, and numerical training: Contribution of core and non-core skills. Progress in Brain Research, Volume 227(2016), 353-388. https://doi.org/https://doi.org/10.1016/bs.pbr.2016.04.009

NCTM. (2000). Six Principles for School Mathematics. Reston: NCTM.

NCTM. (2003). NCATE / NCTM Program Standards ( 2003 ) Programs for Initial Preparation of Mathematics Teachers, 1-7.

Polman, J., Hornstra, L., \& Volman, M. (2020). The meaning of meaningful learning in mathematics in upper-primary education. Learning Environments Research. https://doi.org/https://doi.org/10.1007/s10984-020-09337-8

Polya, G. (1954). How to solve it? Princeton University Press.

Rangkuti, D. Y., Susanto, \& Yuliati, N. (2018). I j r s m. International Journal of Research Science and Management, 5(7), 13-19. https://doi.org/10.5281/zenodo.1307392

Reikerås, E., Moser, T., \& Tønnessen, F. E. (2017). Mathematical skills and motor life skills in toddlers: do differences in mathematical skills reflect differences in motor skills? European 
Early Childhood Education Research Journal, 25(1), 72-88. https://doi.org/https://doi.org/10.1080/1350293X.2015.1062664

Schroeder, T. L. (1993). Research Symposium: Mathematical Connections: Instances from Research Mathematical Connections: Two Cases from an Evaluation of Students ' Mathematical Problem Solving. Mathematics \& Science Education Department University of British Columbia Presented.

Setapa, M., Mustapha, W. A. H. ., Kanafiah, S. F. H. ., \& Zaman, L. . (2016). A Study of Students' Perception toward Mathematic. Journal of Applied Environmental and Biological Sciences, 6(7S), 28-33.

Simon, M. A. (2017). Explicating mathematical concept and mathematical conception as theoretical constructs for mathematics education research. Educ Stud Math, 94 (2017), 117-137. https://doi.org/https://doi.org/10.1007/s10649-016-9728-1

Siniguian, M. T. (2017). Students have difficulty in solving mathematical problems. International Journal of Advanced Research in Engineering and Applied Sciences, 6(2), 1-12.

Siregar, R., \& Siagian, M. D. (2019). Mathematical connection ability : teacher's perception and experience in learning Mathematical connection ability: teacher's s perception and experience in learning. Journal of Physics: Conference Series, 1315(2019). https://doi.org/10.1088/1742-6596/1315/1/012041

Tambychik, T., Meerah, T. S. M., \& Aziz, Z. (2010). Mathematics Skills Difficulties: A Mixture of Intricacies. Procedia Social and Behavioral Sciences, 7(C), 171-180. https://doi.org/10.1016/j.sbspro.2010.10.025

Vergnaud, G. (1997). The nature of mathematical concepts. In T. Nunes \& P. Bryant (Eds.), Learning and teaching mathematics: An international perspective (pp. 5-28). East Sussex, UK: Psychology Press.

Williams, A. (2015). Does Mathematical Ability Predict Career Success. Scientific American, 28(2). https://doi.org/10.1038/scientificamerican0215-28a

Yumiati, \& Haji, S. (2018). The ability of students ' mathematical connection based on school level in junior high school Ability of students' mathematical connection based on school level in junior high school. IOP Conf. Series: Journal of Physics: Conf. Series 1116 (2018) 022047. https://doi.org/https://doi.org/10.1088/1742-6596/1 116/2/022047

Zengin, Y. (2019). Development of mathematical connection skills in a dynamic learning environment. Education and Information Technology, 24, 2175-2194. https://doi.org/https://doi.org/https://doi.org/10.1007/s10639-019-09870-x 